Supporting information

\title{
Highly birefringent polymer films from the photo-crosslinking polymerisation of bistolane-based methacrylate monomers
}

Yuki Arakawa $^{\text {a,b }}$, Hiroki Kuwahara ${ }^{a}$, Koichi Sakajiria ${ }^{\text {a }}$, Sungmin Kanga ${ }^{\text {a }}$, Mastoshi

Tokita $^{\mathrm{a}^{*}}$ and Gen-ichi Konishi ${ }^{\mathrm{a}^{*}}$

${ }^{a}$ Department of Organic and Polymeric Materials, Tokyo Institute of Technology O-okayama, Meguro-ku, Tokyo 152-8552, Japan

${ }^{\mathrm{b}}$ Department of Environmental and Life Sciences, Graduate School of Engineering, Toyohashi University of Technology, Tempaku-cho, Toyohashi, Aichi 441-8580, Japan E-mail:mtokita@polymer.titech.ac.jp; konishi.g.aa@m.titech.ac.jp 


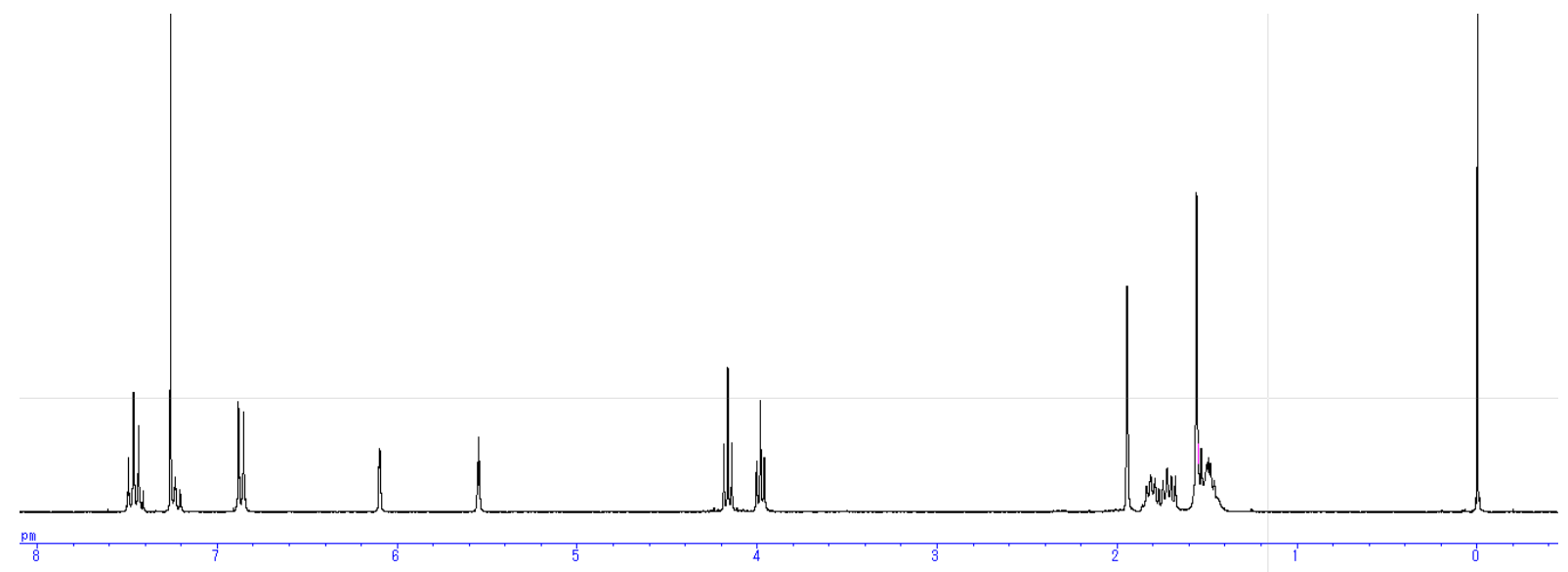

Figure S1. ${ }^{1} \mathrm{H}$ NMR spectrum of monomer $1\left(300 \mathrm{MHz}, \mathrm{CDCl}_{3}\right)$.

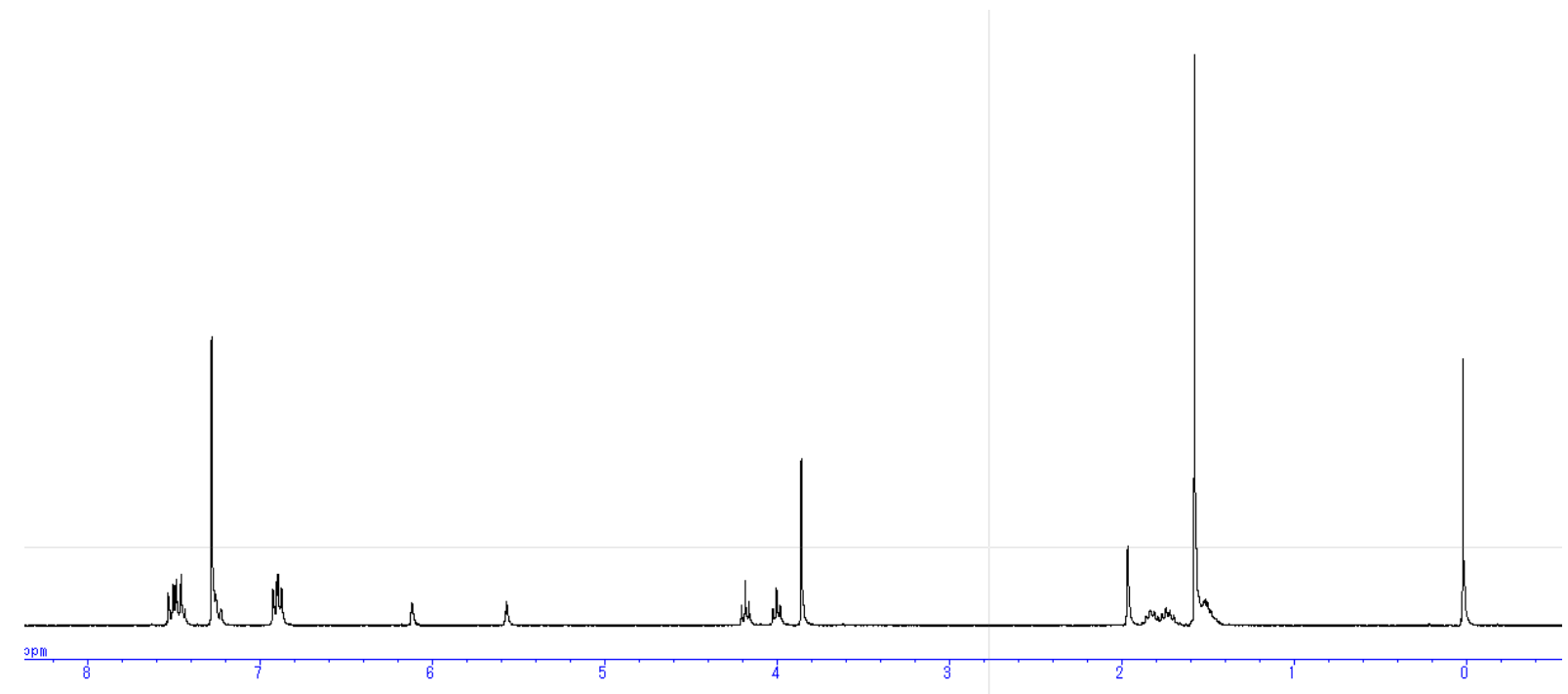

Figure S2. ${ }^{1} \mathrm{H}$ NMR spectrum of monomer $2 \quad\left(300 \mathrm{MHz}, \mathrm{CDCl}_{3}\right)$. 


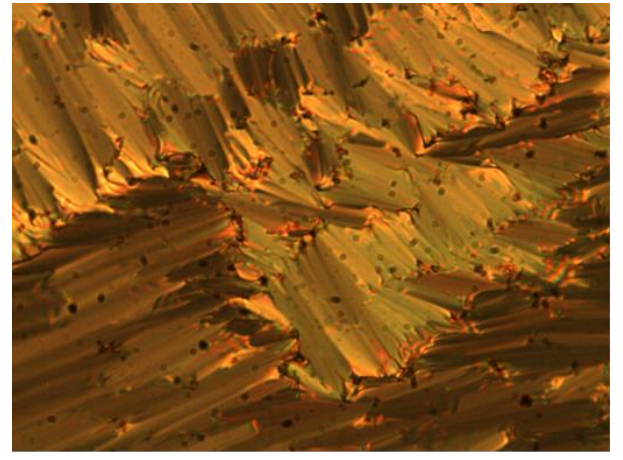

(a)

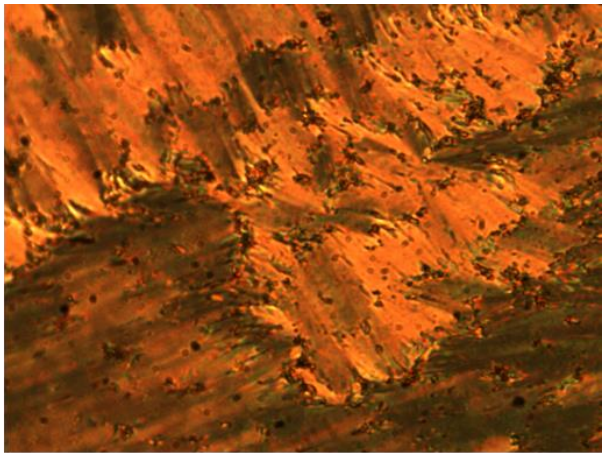

(b)

Figure S3. POM images for (a) the fan-shaped texture of the SmA phase of $\mathbf{1}$ at $95{ }^{\circ} \mathrm{C}$, and (b) the broken fan-shaped texture of the $\mathrm{SmC}$ phase of $\mathbf{1}$ at $70{ }^{\circ} \mathrm{C}$ (obtained with a homogeneous alignment cell).

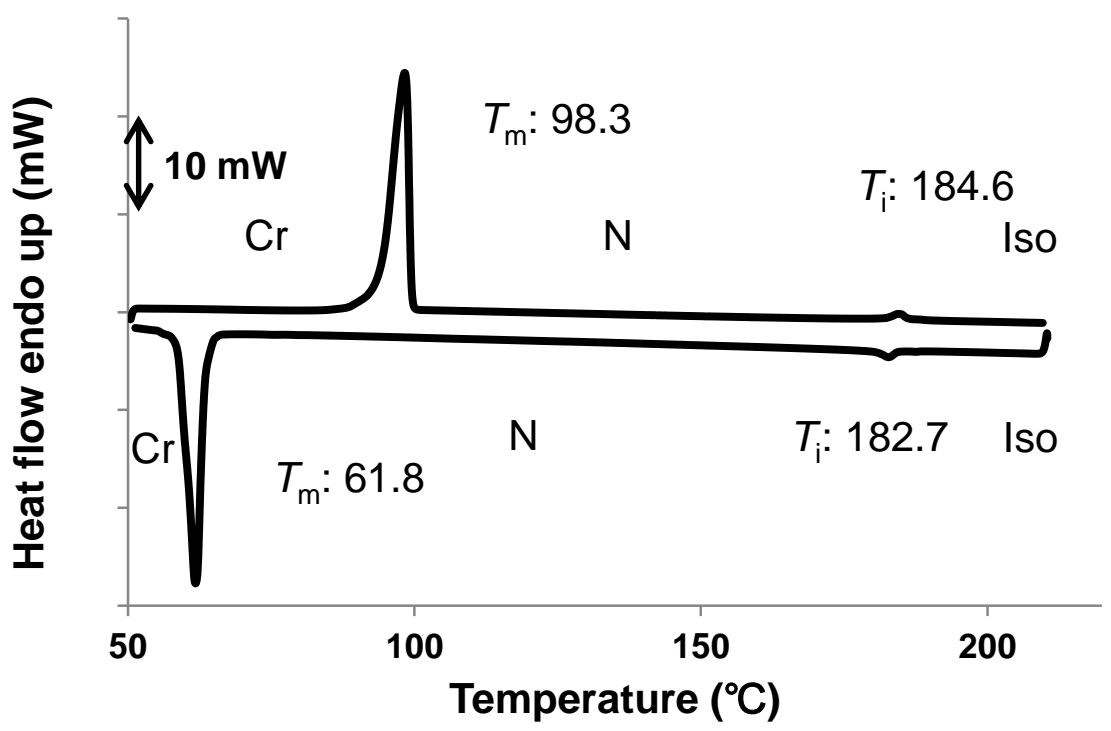

Figure S4. DSC thermogram of $\mathbf{4 a}$. 


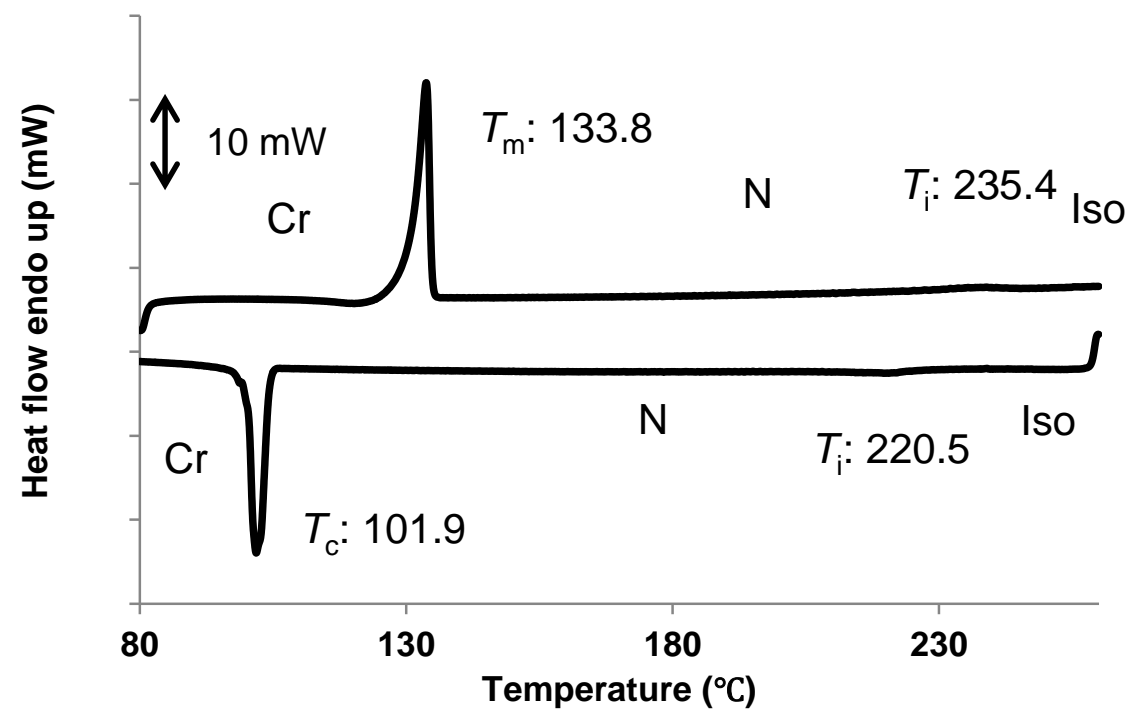

Figure S5. DSC thermogram of $\mathbf{4 b}$.

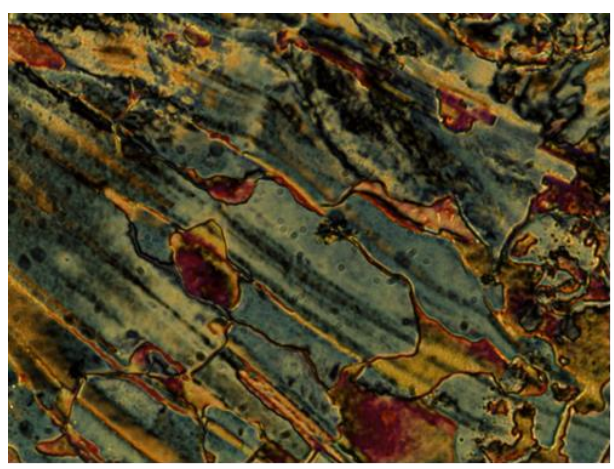

(a)

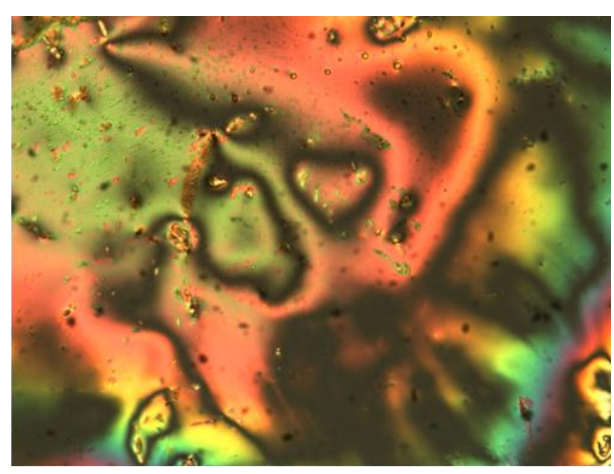

(b)

Figure S6. POM images of (a) the marble texture of the $\mathrm{N}$ phase at $180{ }^{\circ} \mathrm{C}$ for precursor $\mathbf{4 a}$, and (b) the marble texture of the $\mathrm{N}$ phase at $180{ }^{\circ} \mathrm{C}$ for precursor $\mathbf{4 b}$. 


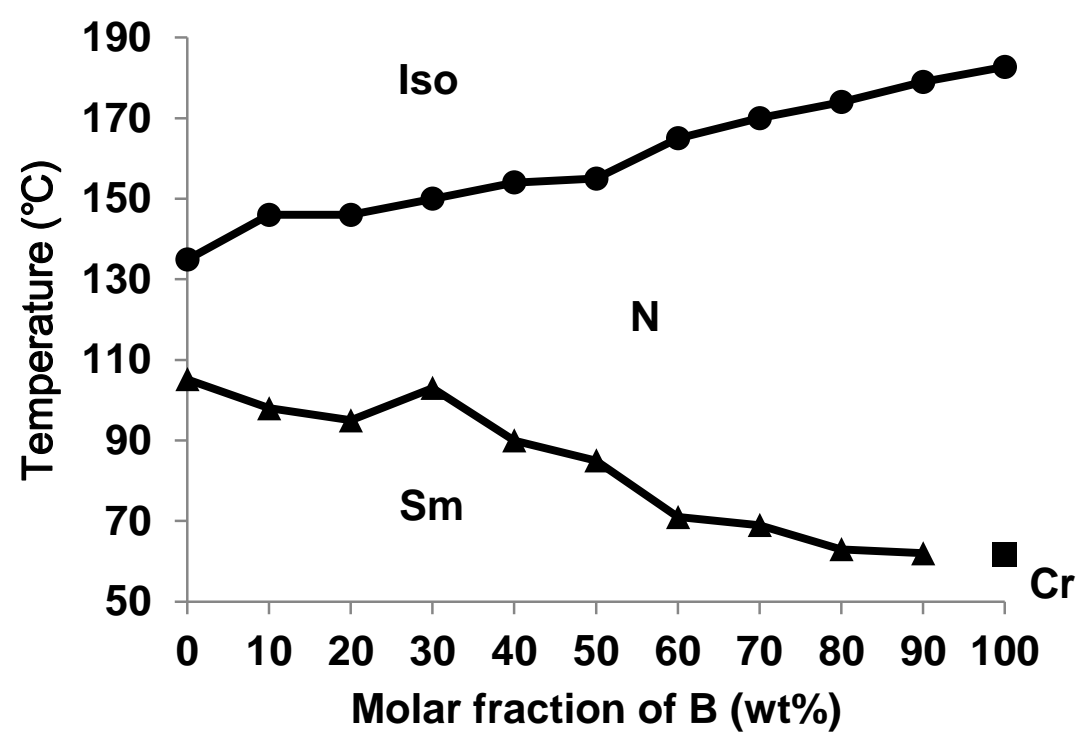

Figure S7. Phase diagram for the mixture of $\mathbf{1}$ and $\mathbf{2}$, obtained by POM of a cooling scan.

\section{Birefringence measurement}

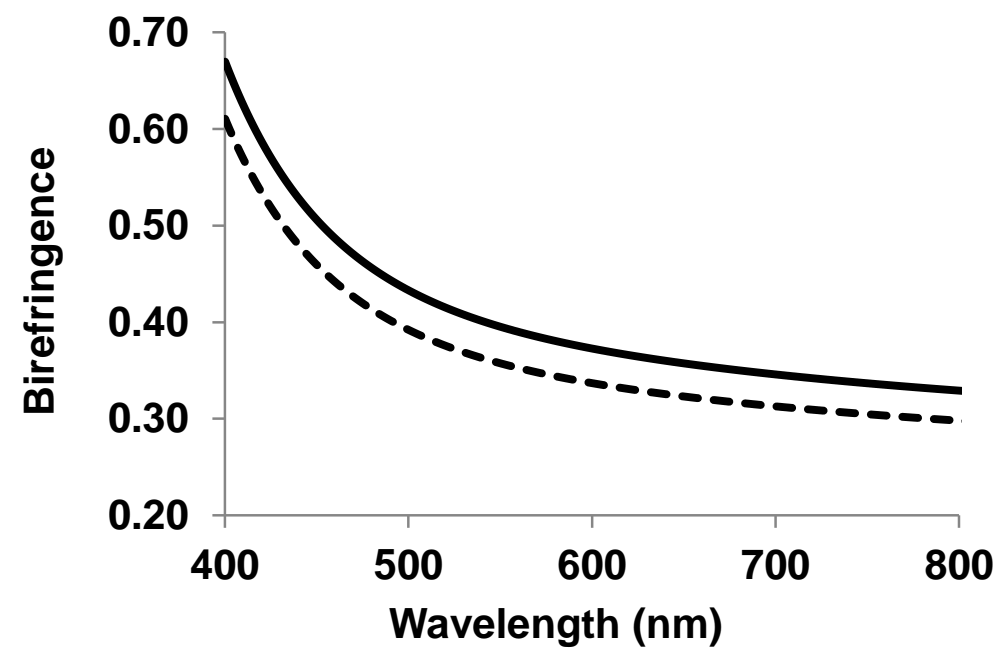

Figure S8. Wavelength dispersion of $\Delta n$ of the $20 / 80(w / w)$ mixture of 1 and 2 . The dashed line and the solid line refer to $T_{\mathrm{m}}+10{ }^{\circ} \mathrm{C}$ prior to polymerisation, and room temperature posterior to polymerisation, respectively. 